\title{
Erratum to: Serological response and protection level evaluation in chickens exposed to grains coated with 12 Newcastle disease virus for effective oral vaccination of village chickens
}

Reta D. Abdi ${ }^{1,2^{*}+}$, Kassaw Amssalu Tadesse ${ }^{3+}$, Olana Merera ${ }^{4}$, Yilkal Asfaw ${ }^{1}$, Eseyas Gelaye ${ }^{5}$, Marta Yami ${ }^{5}$ and Teshale Sori ${ }^{1}$

\section{Erratum}

The original article [1] contains an error in the author list that was carried forward by the production team handling this article.

The co-lead author, Kassaw Amssalu Tadesse's name is incorrectly displayed as 'Kasahun Amsalu'; this should instead be displayed as 'Kassaw Amssalu Tadesse'.

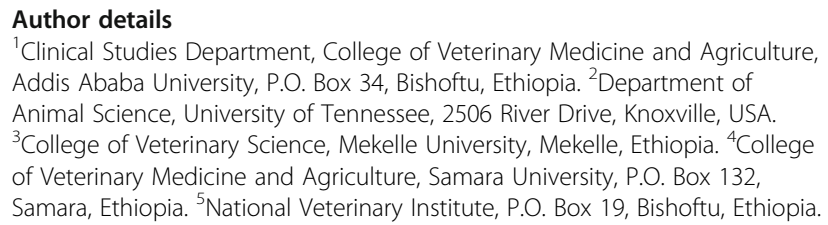

${ }^{1}$ Clinical Studies Department, College of Veterinary Medicine and Agriculture, Addis Ababa University, P.O. Box 34, Bishoftu, Ethiopia. ${ }^{2}$ Department of Animal Science, University of Tennessee, 2506 River Drive, Knoxville, USA. ${ }^{3}$ College of Veterinary Science, Mekelle University, Mekelle, Ethiopia. ${ }^{4}$ College of Veterinary Medicine and Agriculture, Samara University, P.O. Box 132, Samara, Ethiopia. ${ }^{5}$ National Veterinary Institute, P.O. Box 19, Bishoftu, Ethiopia.

Received: 1 December 2016 Accepted: 1 December 2016

Published online: 08 December 2016

\section{Reference}

1. Abdi RD, et al. Serological response and protection level evaluation in chickens exposed to grains coated with 12 Newcastle disease virus for effective oral vaccination of village chickens. BMC Vet Res. 2016;12:150. doi:10.1186/s12917-016-0785-6.

\footnotetext{
*Correspondence: retaduguma@gmail.com; rabdi@utk.edu

${ }^{\dagger}$ Equal contributors

${ }^{1}$ Clinical Studies Department, College of Veterinary Medicine and Agriculture, Addis Ababa University, P.O. Box 34, Bishoftu, Ethiopia

${ }^{2}$ Department of Animal Science, University of Tennessee, 2506 River Drive, Knoxville, USA
} 